\title{
Virological Environmental Analysis
}

\author{
Maurizio Anselmi, Maurizio Divizia* \\ Department of Biomedicine and Prevention, Tor Vergata University, Faculty of Medicine, Via Montpellier, Rome 100133 , \\ Italy
}

Corresponding Author Email: divizia@uniroma2.it

https://doi.org/10.18280/ijsse.110423

Received: 20 January 2021

Accepted: 12 June 2021

\section{Keywords:}

cell cultures, methodology, molecular methods, virological analysis, water

To fully understand the contamination of drinking water it would be more accurate to mention the water matrix including groundwater and mineral waters, surface waters, treated and untreated urban wastewater, seawater and food treated with contaminated water.

The first barrier in the virological analysis of water is represented by the fact that viruses are endocellular parasites, so, they need a cell line in order to multiply, unlike bacteria that need only selective medium. Therefore, ensuring specific application of cell lines, according to the different viruses to be isolated, raises the costs of virological analysis compared to bacteriological tests.

All this explains why over the years the authors have focused their attention on microorganisms to be considered "indicators of viral presence", as it is the case for bacteriological indicators in the analysis of drinking water for human consumption. Initially, the attention of the authors focused on total and / or fecal coliforms, but already in 1988 Grabow et al. [1] demonstrated how these indicators were inadequate even in the presence of viral contamination. Subsequently, the attention was shifted toward bacteriophages, such as somatic phages, F-plus phages and finally the B40-8 phage of Bacteroides fragilis. The same Author was able to demonstrate a positive correlation between somatic coliphages-fecal streptococci-enterovirus but only in untreated wastewater, where any possible correlation is likely due to the high degree of contamination of these waters.

From 1950 researchers started to talk about the presence of viruses in water defined as "filter bacteria" or "non-bacteria" responsible for human diseases. On the other hand, it is the man (healthy or sick) who produces viruses that, when eliminated in the wastewater, causes the contamination of the water and food like mussels.

The first problem related to virological research in waters is the time that elapses between the reporting of the epidemic and the virological analysis itself, due to the incubation period of diseases caused by enteric viruses. In many cases the delay is so long that the classic methods are not always able to identify the virus, which could be due to low concentration levels. For this reason, the presence of enteric viruses is linked to epidemiological evidence and not to the presence of specific viruses. The first studies developed in the United States starting from 1950 were Cleveland, Tecumseh, and Virus Watch Program studies. In these studies, the incidence of gastrointestinal disorders documented was ranging from 0.5 2.0 episodes / year / person. In 1956, Hodges et al. [2] analysed 362 cases of gastroenteritis and found: 116 cases were caused by bacteria, 56 co-associated with other diseases, 63 of food origin, 45 by drugs, 18 by particular situations and 61 of "undetermined" origin. In 1991 Payment et al. [3] studied 307 families using tap water and 299 families using the same water but purified by reverse osmosis. This analysis showed a significant difference of the incidence person/year/gastroenteritis ( $\mathrm{P}<0.01)$. More recently (1997) the same author [4] highlighted similar results with a peak of incidence in the autumn-winter period.

The enteric viruses found in waters belong to 7-9 different families, in total over 100 serotypes, each with different characteristics and resistance to environmental aspects. For example, the hepatitis A virus and Rotaviruses show a higher resistance towards disinfectants with respect to other enteric viruses and/or bacteria.

Virological analysis is based on three basic steps: sample collection, sample concentration, isolation and identification of any present virus. The first step relates to the volume taken for the analyses, which in the case of a drinking water sample is required to be few hundreds liters. It is well understood that a sample of this size cannot be transported to the laboratory and must be concentrated directly in the field (primary concentration) and then reconcentrated in the laboratory (secondary concentration) (Table 1). Over the years, the Authors have developed often similar or extremely complex methods whose efficiency in virus recovery could be extremely variable. On the other hand, each concentration step 
inevitably involves loss of present viruses which reduces the possibility of isolating of any viruses present.

Table 1. Techniques for water concentration

\begin{tabular}{ccc}
\hline \multicolumn{2}{c}{ Virological Environmental Analysis } \\
First step & Second step & $\begin{array}{c}\text { Final } \\
\text { concentration }\end{array}$ \\
\hline $\begin{array}{c}\text { Field } \\
\text { Concentration } \\
\text { (Cartridge) }\end{array}$ & $\begin{array}{c}\text { Field } \\
\text { Concentration } \\
\text { (Membranes) } \\
\text { Ultraconcentration } \\
\text { Acid Precipitation }\end{array}$ & PEG6000 \\
& \\
\hline
\end{tabular}

The third step is the isolation and identification of viruses from concentrated samples. Biological, immunological systems and electron microscopy are procedures not any more utilized for this purpose. Isolation on cell cultures represents proof of the presence of infectious viruses and therefore a concrete risk in public health (Table 2). The success of isolation on cell systems is linked to a series of variables such as the co-presence of multiple enteric viruses, the toxicity of the sample, the physiological state of the cells, the need to use multiple cell lines, with an evident increase in costs. Additionally, different replication speed of some viruses could mask the presence of slower growing viruses. Furthermore, not all viruses are capable to multiply on cellular systems such as Noroviruses and not all induce an evident cytopathic effect as polioviruses; others multiply without inducing any alteration of the cellular monolayer.

Table 2. Methods for virus isolation

\begin{tabular}{cc}
\hline \multicolumn{2}{c}{ Virological Environmental Analysis } \\
\hline Biological methods & Animal inoculation \\
Cell culture \\
Immunological methods & Immunofluorescence \\
& Elisa test \\
& Radioimmunoassay \\
& Radioimmunofocus \\
Molecular methods & Probe (DNA or RNA) \\
& PCR \\
& Real-time RT-PCR \\
\hline
\end{tabular}

In recent years, alongside traditional methods, have been developed biological-molecular methods such as hybridization with probes and polymerase chain reaction tests.

The hybridization test with radioactive-labeled probes stimulates the spread of molecular methods in the environmental analysis but at the same time the use of radioactive (hot probes) limited the spread of the hybridization method. Only later, the radioactive was replaced with enzymatic or fluorescent labelled probes (cold probes). In 1988 Cova et al. [5] demonstrated how viral strains could be identified by choosing suitable areas of the viral genome. Also Jansen et al. [6] brought in 1990 the sensitivity of the RT-PCR method to only 3-30 viral particles per test. The use of molecular probes for the detection of enteric viruses in the environmental samples therefore represents an important alternative to the traditional methods. It has a single limiting factor represented by the sensitivity of the test which makes it applicable only for heavily polluted waters.

In a previous study, Divizia et al. [7], using samples of the Tiber river, showed a lower sensitivity of the traditional method (Elisa: 15.3\%; cell cultures: 23\%) compared to molecular tests (hybridization: 38.4\%; RT-PCR: 67\%) (Table
3). The study confirmed the high circulation of viruses. The usefulness of the RT-PCR technique is also linked to the possibility not only of identifying the virus, but also of genotyping the isolated viral strain as poliovirus (Sabin and Wild) or the different genotypes of hepatitis A, etc. Serres et al. [8] in an epidemic of hepatitis A in Canada clearly demonstrated the common origin of the viral strain, following the spread of the virus in artesian wells with a depth of more than 60 meters.

Table 3. Sensibility of different methods

\begin{tabular}{cc}
\hline \multicolumn{2}{c}{ Virological Environmental Analysis } \\
\hline Cell culture & Probes \\
$23 \%$ & $38,4 \%$ \\
Test ELISA & P.C.R. \\
$15,3 \%$ & $66 \%$ \\
\hline
\end{tabular}

However, one of the fundamental problems in the application of the RT-PCR reaction in the environmental field is linked to the presence of inhibitors of enzymatic reactions, as the composition of wastewater samples, homogenates of mussels or sludge.

The PCR method also appears to overcome the problems encountered with the hybridization. The test consists of a selective enzymatic amplification of a target sequence of the genomic DNA (or cDNA from RNA genome) with an exponential enrichment of type $2^{\mathrm{N}}$ with $\mathrm{N}$ equal to the number of replication cycles. It is clear that this method presents useful prospects for application to drinking water. Obviously the molecular biology are not able to discriminate between inactivated viruses and infectious viruses, extremely important in public health.

The RT-PCR relationship in the epidemiological field is important, to evaluate the spread of viruses, the introduction of new strains in certain areas or genomic variants of an already present virus. In a study carried out in Albania [9], conducted to evaluate the viral contamination of the waters, strains of Poliovirus were isolated from the environment, in particular from the Lana river, two months before the first case of poliomyelitis in humans in the city. The virological analysis clearly demonstrated that the viral strains isolated were atypical strains, isolated both from the environment and from infected subjects.

In conclusion, environmental virological analysis is still a sufficiently complex procedure that it cannot be applied by all laboratories.

\section{REFERENCES}

[1] Grabow, W.O.K., Idema, G.K., Coubrough, P., Bateman, B.W. (1989). Selection of indicator systems for human viruses in polluted seawater and shellfish. Water Science and Technology, 21(3): 111-117. https://doi.org/10.2166/wst.1989.0087

[2] Hodges, R.G., McCorkle, L.P., Badger, G.F. (1956). A study of illness in a group of Cleveland familis. The occurance of gastrointestinal symptoms. American Journal of Hygiene, 64: 349-356.

[3] Payment, P., Franco, E.D.U.A.R.D.O., Richardson, L., Siemiatycki, J. (1991). Gastrointestinal health effects associated with the consumption of drinking water produced by point-of-use domestic reverse-osmosis filtration units. Applied and Environmental 
Microbiology, 57(4): 945-948.

[4] Payment, P., Siemiatycki, J., Richardson, L., Renaud, G., Franco, E., Prevost, M. (1997). A prospective epidemiological study of gastrointestinal health effects due to the consumption of drinking water. International Journal of Environmental Health Research, 7(1): 5-31. https://doi.org/10.1080/09603129773977

[5] Cova, L., Kopecka, H., Aymard, M., Girard, M. (1988). Use of cRNA probes for the detection of enteroviruses by molecular hybridization. Journal of Medical Virology, 24(1): 11-18. https://doi.org/10.1002/jmv.1890240103

[6] Jansen, R.W., Siegl, G., Lemon, S.M. (1990). Molecular epidemiology of human hepatitis A virus defined by an antigen-capture polymerase chain reaction method. Proceedings of the National Academy of Sciences, 87(8): 2867-2871. https://doi.org/10.1073/pnas.87.8.2867
[7] Divizia, M., Degener, A.M., Ripanti, L., Argentini, C., Perez Bercoff, R., Panà, A. (1991). Indagine sullo stato di salute del fiume Tevere. L'Igiene Moderna, 95: 715729.

[8] Serres, G.D., Cromeans, T.L., Levesque, B., Brassard, N., Barthe, C., Dionne, M., Margolis, H.S. (1999). Molecular confirmation of hepatitis A virus from well water: epidemiology and public health implications. The Journal of Infectious Diseases, 179(1): 37-43. https://doi.org/10.1086/314565

[9] Divizia, M., Palombi, L., Buonomo, E., Donia, D., Ruscio, V., Equestre, M., Degener, A.M. (1999). Genomic characterization of human and environmental polioviruses isolated in Albania. Applied and Environmental Microbiology, 65(8): 3534-3539. https://doi.org/10.1128/AEM.65.8.3534-3539.1999 